\title{
The Danish National Penile Cancer Quality database
}

\author{
Jakob Kristian Jakobsen' \\ Buket Öztürk² \\ Mette Søgaard ${ }^{2}$ \\ 'Department of Urology, ${ }^{2}$ Department \\ of Clinical Epidemiology, Aarhus \\ University Hospital, Aarhus Nord, \\ Denmark
}

This article was published in the following Dove Press journal:

Clinical Epidemiology

25 October 2016

Number of times this article has been viewed
Aim of database: The Danish National Penile Cancer Quality database (DaPeCa-data) aims to improve the quality of cancer care and monitor the diagnosis, staging, and treatment of all incident penile cancer cases in Denmark. The aim is to assure referral practice, guideline adherence, and treatment and development of the database in order to enhance research opportunities and increase knowledge and survival outcomes of penile cancer.

Study population: The $\mathrm{DaPeCa}$-data registers all patients with newly diagnosed invasive squamous cell carcinoma of the penis in Denmark since June 2011.

Main variables: Data are systematically registered at the time of diagnosis by a combination of automated data-linkage to the central registries as well as online registration by treating clinicians. The main variables registered relate to disease prognosis and treatment morbidity and include the presence of risk factors (phimosis, lichen sclerosus, and human papillomavirus), date of diagnosis, date of treatment decision, date of beginning of treatment, type of treatment, treating hospital, type and time of complications, date of recurrence, date of death, and cause of death.

Descriptive data: Registration of these variables correlated to the unique Danish ten-digit civil registration number enables characterization of the cohort, individual patients, and patient groups with respect to age; 1-, 3-, and 5-year disease-specific and overall survival; recurrence patterns; and morbidity profile related to treatment modality. As of August 2015, more than 200 patients are registered with $\sim 65$ new entries per year.

Conclusion: The DaPeCa-data has potential to provide meaningful, timely, and clinically relevant quality data for quality maintenance, development, and research purposes.

Keywords: penile cancer, squamous cell carcinoma of the penis, clinical quality, national database, epidemiology, treatment

\section{Introduction}

Penile cancer is rare, and in Denmark, it has traditionally been diversely managed in dermatology, surgery, urology, and oncology without management guidelines and systematic quality monitoring. In 2009, a centralization of service to two university hospitals and two specialties, urology and oncology, favored continuous prospective data collection and initiated several quality improvements. The purpose of this study is to describe the Danish National Penile Cancer Quality database (DaPeCa-data).

\section{Aim of database}

The DaPeCa-data is a nationwide clinical cancer database with prospective data collection since June 2011 (Table 1). By the means of the Danish Civil Registration System, 
Table I Overview of DaPeCa-data

\begin{tabular}{|c|c|c|}
\hline General information & & Comments \\
\hline Patient population & $\begin{array}{l}\text { Incident penile cancer (penile } \\
\text { squamous cell carcinoma) }\end{array}$ & Data collection since June 201I \\
\hline Data coverage & $\begin{array}{l}\text { Nationwide (centralized care } \\
\text { since } 2009 \text { to two centers) }\end{array}$ & $\begin{array}{l}\text { Two urological, two oncological, and two pathological sites participating in data } \\
\text { registration }\end{array}$ \\
\hline Data collection & Prospective & $\begin{array}{l}\text { Data linkage from central registry combined with online prospective data } \\
\text { collection of key clinical variables by treating clinicians }\end{array}$ \\
\hline $\begin{array}{l}\text { Clinical quality } \\
\text { indicators }\end{array}$ & $\mathrm{N}=14$ & \\
\hline $\begin{array}{l}\text { Clinical data } \\
\text { registration forms }\end{array}$ & $\begin{array}{l}\text { Diagnosis clinical data } \\
\text { registration form } \\
\text { Treatment clinical data } \\
\text { registration form } \\
\text { Recurrence form } \\
\text { Follow-up form }\end{array}$ & \\
\hline $\begin{array}{l}\text { PROM } \\
\text { questionnaires }\end{array}$ & $\begin{array}{l}\text { Pilot study since January } 2013 \\
\text { At time of diagnosis } \\
\text { I-year follow-up } \\
\text { 2-year follow-up } \\
\text { 3-year follow-up }\end{array}$ & \\
\hline $\begin{array}{l}\text { Treatments } \\
\text { variables }\end{array}$ & $\begin{array}{l}\text { Surgery } \\
\text { Radiation therapy }\end{array}$ & $\begin{array}{l}\text { Primary penile surgery } \\
\text { Lymph node surgery } \\
\text { Inguinal } \\
\text { Illiacal } \\
\text { Yes/no }\end{array}$ \\
\hline $\begin{array}{l}\text { Pathology } \\
\text { variables }\end{array}$ & Biopsy definition & $\begin{array}{l}\text { SNOMED codes P306I0 biopsy, P306II excisional biopsy, P306 I } 3 \text { punch biopsy, } \\
\text { P306 IA incisional biopsy, or P30620 resection combined with SNOMED code } \\
\text { T02530 skin on penis, T02540 skin on prepuce, T76330 prepuce, T7600 penis, or } \\
\text { T762 I0 corpus cavernosum penis }\end{array}$ \\
\hline & Penectomy definition & $\begin{array}{l}\text { SNOMED codes } \mathrm{P} 306 \mathrm{X} 0 \text { ectomy, or } \mathrm{P} 306 \mathrm{X} 4 \text { tumorectomy combined with } \\
\text { SNOMED codes T02530 skin on penis, T02540 skin on prepuce, T76330 prepuce, } \\
\text { T7600 penis, or T76210 corpus cavernosum penis }\end{array}$ \\
\hline & $\begin{array}{l}\text { Lymphadenectomy definition } \\
\text { and sentinel node biopsy } \\
\text { definition }\end{array}$ & $\begin{array}{l}\text { SNOMED code T088II lymph node in the right inguinal region, T088I } 2 \text { lymph node } \\
\text { in the left inguinal region, T088IB sentinel lymph node in the right inguinal region, } \\
\text { or T088IC sentinel lymph node in the left inguinal region, squamous cell metastasis } \\
\text { M80706, no extranodal extension M094B0, extranodal extension M094B I }\end{array}$ \\
\hline & Grade of differentiation & $\begin{array}{l}\text { High grade of differentiation (SNOMED code } \text { EYYDI), moderate differentiation } \\
\text { (SNOMED code } \text { EYYD2), or low grade of differentiation (SNOMED code } / \text { EYYD3) }\end{array}$ \\
\hline & TNM stage & $\begin{array}{l}\mathrm{pT} \text { is (SNOMED code } / \text { FFI8I0), pTa (SNOMED code } / \text { EFI8IA), pTx (SNOMED } \\
\text { code } / \text { EFI870), pTIa (SNOMED code } / \text { EFI83I), pTIb (SNOMED code } / \text { EFI832), } \\
\text { pT2 (SNOMED code } / \text { EFI840), pT3 (SNOMED code } / \text { EFI850), and pT4 } \\
\text { (SNOMED code } / \text { EFI860) }\end{array}$ \\
\hline & Surgical margin & $\begin{array}{l}\text { Negative margin (SNOMED code M09400) and positive margin (SNOMED code } \\
\text { M0940I) }\end{array}$ \\
\hline & Histological type & Squamous cell carcinoma (SNOMED code M80703) \\
\hline & Histological subtype & $\begin{array}{l}\text { Classical (SNOMED code M80703), verrucous carcinoma (SNOMED code } \\
\text { M805I3), basaloid (SNOMED code M8I233), sarcomatoid (SNOMED code } \\
\text { M80333), and adenosquamous (SNOMED code M85603) }\end{array}$ \\
\hline $\begin{array}{l}\text { Administrative } \\
\text { variables }\end{array}$ & $\begin{array}{l}\text { Region } \\
\text { Hospital site } \\
\text { Others }\end{array}$ & \\
\hline
\end{tabular}

Note: TNM cancer stage classification according to UICC.

Abbreviations: DaPeCa-data, Danish National Penile Cancer Quality database; PROM, patient-reported outcome measure; TNM, tumor lymph node and metastasis; UICC, Union for International Cancer Control; SNOMED, Systematized Nomenclature of Human Medicine.

the database enables individual data collection and holds potential for a large number of data-linkage opportunities to existing and longstanding national registries on, for example, socioeconomic and pharmacological parameters. To our knowledge, within penile cancer registries, this possibility is only matched by the Swedish penile cancer registry enabling DaPeCa-data to supply important population-based data on this rare entity. DaPeCa-data is affiliated with the Danish 
National Penile Cancer Quality group (DaPeCa-group), which consists of clinical and paraclinical experts from the specialties oncology, pathology, and urology. The group is responsible for developing national clinical guidelines for the staging, treatment, and follow-up of penile cancer in Denmark and decides on quality indicators and indicator standards based on experience and available literature. ${ }^{1}$

The overall aim of DaPeCa database and DaPeCa-group is to improve the quality of cancer care for penile cancer patients in Denmark. More specifically, the purpose of DaPeCa-data is to systematically collect key clinical variables on all incident penile cancer patients in Denmark for quality improvement and research.

The DaPeCa-data monitors clinical management of penile cancer. Penile cancer care in Denmark is centralized to two university centers. ${ }^{2}$ The $\mathrm{DaPeCa}$-data monitors referral practice from regional hospitals and private practices within surgery/urology, dermatology, and general practice and monitors guideline adherence at the treating centers. The DaPeCa-data aims to assure modern staging and treatment of patients with penile cancer and to provide data for development of the research field.

\section{Study population}

Penile cancer is a rare disease with an incidence in developed countries in the range of $0.5-2.5 / 100,000$ population/year. ${ }^{3}$ The incidence in Denmark is estimated to be $0.8 / 100,000$ population/year, and the mean age at diagnosis is 65 years. ${ }^{4}$ Data on $\sim 65$ patients are entered into the database each year, which has currently accumulated to more than 200 entries. Due to the rarity of the disease, it is a high priority of the DaPeCa-group and DaPeCa-data to collaborate with other databases in Scandinavia and in other Northern European countries with comparable populations. Currently, an application for a common Scandinavian database is under preparation with the success of the common Scandinavian childhood cancer databases as a model. ${ }^{5}$

\section{Inclusion criteria and exclusion criteria}

The $\mathrm{DaPeCa}$-data registers all patients with newly diagnosed invasive squamous cell carcinoma of the penis in Denmark.

Patients with penile tumors with nonsquamous cell carcinoma histopathological features, such as sarcoma, melanoma, lymphoma, and metastases, from other cancers are not registered in the $\mathrm{DaPeCa}$-data since each of these entities are covered by other national databases. Tumors of the distal urethra (navicular fossa) are registered if they involve external aspects of penile anatomy. Other primary urethral tumors are not registered.
Inclusion in the database is based on registration of a patient in the Danish Pathology Registry ${ }^{6}$ with relevant Systematized Nomenclature of Human Medicine (SNOMED) codes or registration in the Danish National Patient Registry and the Danish Cancer Registry with relevant ICD codes (DC609, DC609J, DC609K, DC609L, DC609M, DC609N, DC609P, DC609Q, DC609R, DC609S, DC609T, DC609U, and DC609Z). ${ }^{?}$

\section{Main variables and data quality}

The variables currently collected via the online registration interface are listed in Table 2. Online registration by

Table 2 Overview of DaPeCa-data variables

\begin{tabular}{|c|c|}
\hline \multicolumn{2}{|l|}{ Diagnosis } \\
\hline Date of biopsy & Day/month/year \\
\hline \multicolumn{2}{|c|}{$\begin{array}{l}\text { Has the patient been in contact Yes/no } \\
\text { with a highly specialized center? }\end{array}$} \\
\hline \multirow[t]{7}{*}{ Symptoms } & None \\
\hline & Bleeding \\
\hline & Infection \\
\hline & Lymph node enlargement \\
\hline & Wound/tumor on penis \\
\hline & Metastatic symptoms \\
\hline & Others \\
\hline \multirow[t]{7}{*}{ Risk factors } & None \\
\hline & Phimosis \\
\hline & Balanoposthitis \\
\hline & Genital warts \\
\hline & Previous circumcision \\
\hline & Lichen sclerosus \\
\hline & Others \\
\hline \multirow[t]{3}{*}{ Primary diagnosis based on } & Clinical examination alone \\
\hline & Histology \\
\hline & Others \\
\hline \multirow[t]{4}{*}{ Primary tumor localization } & Glans \\
\hline & Prepuce \\
\hline & Penile shaft \\
\hline & Urethra \\
\hline \multirow[t]{6}{*}{ Imaging } & СТ \\
\hline & MRI \\
\hline & US \\
\hline & Lymphoscintigraphy \\
\hline & PET-CT \\
\hline & None \\
\hline \multirow[t]{3}{*}{ Clinical TNM } & $\mathrm{T}$ \\
\hline & $\mathrm{N}$ \\
\hline & M \\
\hline \multicolumn{2}{|l|}{ Treatment } \\
\hline Date of treatment decision & Day/month/year \\
\hline \multirow[t]{6}{*}{ Primary treatment } & Laser \\
\hline & Local excision \\
\hline & Glans amputation \\
\hline & Glans amputation with skin graft \\
\hline & Partial penectomy \\
\hline & Total penectomy \\
\hline
\end{tabular}


Table 2 (Continued)

\begin{tabular}{ll}
\hline Treatment & \\
Lymph node surgery & Yes/no \\
& Bilateral sentinel node/sentinel node \\
& left/sentinel node right \\
& Lymphadenectomy inguinal \\
& Lymphadenectomy iliacal \\
& Curative intent/palliation \\
External beam radiation therapy & \\
(EBRT) & Yes/no \\
Chemotherapy & Yes/no \\
Early complications demanding & Reoperation \\
intervention (<3 months) & Bleeding \\
& Wound infection \\
& Skin necrosis \\
Virus fag type & Meatal stenosis \\
Cause of death & Lymphocele \\
HPV test on primary tumor & Thrombosis \\
& Lymphedema \\
& Erectile dysfunction \\
& Others \\
& No data \\
& Others \\
& \\
& \\
& \\
& \\
& \\
& \\
&
\end{tabular}

Note: [.] Indicates that the virus fag type is entered in free text by the clinician via the database interface.

Abbreviations: CT, computed tomography; DaPeCa-data, Danish National Penile Cancer Quality database; HPV, human papillomavirus; MRI, magnetic resonance imaging; PET-CT, positron emission tomography/computed tomography;TNM, tumor lymph node and metastasis; US, ultrasound.

the urologist responsible for treatment has the advantage of a high level of data quality and variable validity. On the other hand, the registration interface is extensive and difficult to handle in daily practice. Ongoing validation projects of data accumulating via the Danish pathology and Danish patient registries aim to move a considerable part of the data registration toward automated data extraction and validation from these registries by treating clinicians via patient interview and examination or medical record verification. The annual reports published so far have been based mainly on this type of data, and it has turned out that continuous validation and interaction between clinicians and statisticians are of great importance in order to produce a valid and meaningful report. A solid framework for continuous validation algorithms and iterative data checking has to be designed and validated to speed this process up in order to meet the demand of the political visions of close-to real-time quality data production. This process is currently in an early phase, and limited resources are a main challenge.

\section{Follow-up}

DaPeCa-data has promising potential to virtually complete the follow-up of its patient population. All penile cancer patients included in $\mathrm{DaPeCa}$-data can be followed until death or emigration by means of data linkage to the Danish Civil Registration System.

An ongoing effort aims to facilitate automated follow-up prompts to appear at the relevant administrator in order to enter the follow-up data continuously. If this system fails to be implemented, the database will be updated in relation to specific studies with retrieval and addition of relevant data from records and registers via Danish Civil Registration System.

\section{Examples of research}

The group behind the $\mathrm{DaPeCa}$-data is active within the research field and publishes regularly on the topic, $;^{2,8-12}$ however, no research paper as of yet has used data registered in the $\mathrm{DaPeCa}$-data due to the rarity of the disease and the fact that the database was only established in June 2011. The first validation study is under preparation. Since its inception in 2011, DaPeCa-data has annually released a report with analyses of the clinical quality indicators (Table 3 ). However, results and data presented in the annual reports from the initial development years should be interpreted with reservation and caution. As reflected by the most recent annual reports, data validity and completeness has been improving over time, but validation and algorithm optimization is only progressing slowly at the current level of support and funding.

\section{Administrative issues and funding}

The DaPeCa-data is administered in the two centers, such as Copenhagen University Hospital and Aarhus University Hospital, responsible for staging and treatment of the patients. Validation lists of all patients with the diagnosis within the uptake area of the specific center are presented to the database administrators every 3 months. Data are entered into an Internet-based online user interface with integrated range validation by treating clinicians. The completeness of registration is high, in some years approaching 100\%. Data are linked to each patient's unique ten-digit civil personal registration number. The database steering committee consists of clinicians and academic experts representing urology, oncology, and pathology and continuously updates and specifies the quality indicators and the contents of the data profile ensuring a clinically meaningful and realistic dataset. The database receives a limited amount of funding from 
Table 3 Overview of DaPeCa-data quality indicators

\begin{tabular}{|c|c|c|c|c|}
\hline ID & Name & $\begin{array}{l}\text { Format (indicator } \\
\text { standard) }\end{array}$ & Type & $2013-2014$ \\
\hline DaPeCa-indi-I & $\begin{array}{l}\text { Referral pattern: fraction of patients with the diagnosis in contact with a } \\
\text { highly specialized center }\end{array}$ & $>75 \%$ & Process & $93 \%$ \\
\hline DaPeCa-indi-2 & $\begin{array}{l}\text { Sentinel node guideline adherence: fraction of relevant patients (cN0/ } \\
\mathrm{cNx} \text { ) undergoing sentinel node biopsy at diagnosis }\end{array}$ & $>90 \%$ & Process & $96 \%$ \\
\hline DaPeCa-indi-3 & $\begin{array}{l}\text { Recurrence pattern: fraction of patients experiencing recurrence within } \\
\text { five years of primary treatment }\end{array}$ & $<50 \%$ & Result & No data \\
\hline DaPeCa-indi-4 & $\begin{array}{l}\text { Blood transfusion: fraction of patients in need of pre- or postoperative } \\
\text { blood transfusion }\end{array}$ & $<10 \%$ & Process & 0 \\
\hline DaPeCa-indi-5 & 30-day mortality: death within 30 days after primary treatment & $<0.5 \%$ & Result & 0 \\
\hline DaPeCa-indi-6 & $\begin{array}{l}\text { Pathology registration: fraction of patients with registration and coding } \\
\text { of a complete set of key histopathology parameters }\end{array}$ & Under implementation & Process & No data \\
\hline DaPeCa-indi-7 & $\begin{array}{l}\text { I- and 5-year overall survival after invasive penile cancer diagnosis, per } \\
\text { center, and overall }\end{array}$ & Under implementation & Result & No data \\
\hline DaPeCa-indi-8 & $\begin{array}{l}\text { I- and 5-year cancer-specific mortality after invasive penile cancer } \\
\text { diagnosis, per center, and overall }\end{array}$ & Under implementation & Result & No data \\
\hline DaPeCa-indi-9 & $\begin{array}{l}\text { I- and 5-year overall survival after inguinal lymph node dissection for } \\
\text { lymph node-positive penile cancer, per center, and overall }\end{array}$ & Under implementation & Result & No data \\
\hline DaPeCa-indi- 10 & $\begin{array}{l}\text { I- and 5-year cancer-specific mortality after inguinal lymph node } \\
\text { dissection for lymph node-positive penile cancer, per center, and overall }\end{array}$ & Under implementation & Result & No data \\
\hline DaPeCa-indi-I I & $\begin{array}{l}\text { Time from diagnosis to inguinal lymph node dissection for lymph node- } \\
\text { positive penile cancer, per center, and overall }\end{array}$ & Under implementation & Process & No data \\
\hline DaPeCa-indi- 12 & $\begin{array}{l}\text { Total number of in hospital days within } 90 \text { days after inguinal lymph node } \\
\text { dissection for lymph node-positive penile cancer, per center, and overall }\end{array}$ & Under implementation & Result & No data \\
\hline DaPeCa-indi- 13 & $\begin{array}{l}\text { I- and 5-year overall survival after oncological treatment with curative } \\
\text { intent for lymph node-positive penile cancer, per center, and overall }\end{array}$ & Under implementation & Result & No data \\
\hline DaPeCa-indi- 14 & $\begin{array}{l}\text { I- and } 5 \text {-year cancer-specific mortality after oncological treatment with } \\
\text { curative intent for lymph node-positive penile cancer, per center, and } \\
\text { overall }\end{array}$ & Under implementation & Result & No data \\
\hline
\end{tabular}

Notes: cN0, clinically lymph node negative; cNx, clinical lymph node status not assessed/not reported. Abbreviation: DaPeCa-data, Danish National Penile Cancer Quality database; ID, identification.

public sources via the Danish Regions and is independent from private funding. DaPeCa-data is under the auspices of the Danish Multidisciplinary Cancer Groups (DMCG.dk), which is an umbrella organization comprising 24 national cancer groups and clinical databases in Denmark. The urological cancer groups and databases are further organized under the subgroup for Danish Urological Cancer Groups. The DaPeCa-data receives a limited administrative support from the Danish Clinical Quality Improvement Program (RKKP). ${ }^{13}$ Technical support and data management service are provided by the Competence Centre for Health Quality and Informatics (KCKS-Vest), ${ }^{14}$ and epidemiological and statistical support to the annual reports is provided by the Competence Centre for Clinical Epidemiology and Biostatistics, North (KCEB-Nord). ${ }^{15}$ Patient-reported outcome measure data are collected nationwide at both urological treatment centers as a part of an ongoing quality of life and sexuality study. On the basis of this pilot project, which is based on an adapted and validated version of the Scandinavian Prostate
Cancer Group 4 items, a patient-reported outcome measure data collection is planned to commence with a validated set of sexuality and quality of life questionnaire items.

DaPeCa-data collects nationwide health care data in accordance with Danish data protection laws. Laws and procedures for data access to $\mathrm{DaPeCa}$-data are governed by the Data Protection Agency (Datatilsynet) and the Danish Ministry of Health (Sundhedstyrelsen). Applications for data access to DaPeCa-data are reviewed by the Chair and Steering Committee upon application to RKKP. ${ }^{13}$

\section{Conclusion}

$\mathrm{DaPeCa}$-data has been in existence since 2011. More than 200 patients are registered. Validation of the register data sources is ongoing, and the first validation study based on data from the $\mathrm{DaPeCa}$-data is under preparation. With an increased level of support and funding, the important validation iterations could be optimized faster. The DaPeCagroup has already published studies based on medical 
records. Updated information on $\mathrm{DaPeCa}$-data is available at the DaPeCa-group Internet homepage: http://ducg.dk/ dapeca-peniscancer/.

\section{Acknowledgments}

Mary Nguyen Nielsen, MD, PhD student, generously provided the textual framework. This article was funded by the Program for Clinical Research Infrastructure established by the Lundbeck Foundation and the Novo Nordisk Foundation and administered by the Danish Regions. This study was conducted on behalf of the $\mathrm{DaPeCa}$ group.

\section{Disclosure}

The authors report no conflicts of interest in this work.

\section{References}

1. DUCG [webpage on the Internet]. DaPeCa Clinical Guidelines (in Danish); 2013. Available from: http://ducg.dk/dapeca-peniscancer/ kliniske-retningslinjer/. Accessed August 25, 2015.

2. Jakobsen JK, Krarup KP, Kirrander P, et al; Scandinavian Penile Cancer Group (SCAPECA). Penile cancer in Scandinavia: current practice and future perspectives. Scand J Urol. 2014;2:1-3.

3. Hakenberg OW, Comperat E, Minhas S, Necchi A, Protzel C, Watkin N [webpage on the Internet]. EAU Guidelines on Penile Cancer; 2014. Available from: uroweb.org/guideline/penile-cancer/. Accessed September 09, 2014.

4. Ulff-Moller CJ, Simonsen J, Frisch M. Marriage, cohabitation and incidence trends of invasive penile squamous cell carcinoma in Denmark 1978-2010. Int J Cancer. 2013;133(5):1173-1179.
5. NOPHO [webpage on the Internet]. SIOP Europe, the European Society for Paediatric Onclogy. Available from: http://www.nopho. org/organization/history/NOPHO $\% 20$ history $\% 20$ SIOPE $\% 20$ news $\% 20$ 2014-02.pdf. Accessed February 19, 2016.

6. Patobank [homepage on the Internet]. The Danish Pathology Registry. Available from: http://www.patobank.dk/. Accessed 25 August, 2015.

7. Lynge E, Sandegaard JL, Rebolj M. The Danish National Patient Register. Scand J Public Health. 2011;39(7 suppl):30-33.

8. Jakobsen JK. A urologist's contemporary guide to penile cancer. Scand J Urol. Epub 2015 Aug 14.

9. Jakobsen JK, Alslev L, Ipsen P, et al. DaPeCa-3: promising results of sentinel node biopsy combined with F-fluorodeoxyglucose positron emission tomography/computed tomography in clinically lymph nodenegative patients with penile cancer - a national study from Denmark. BJU Int. Epub 2015 Jul 28.

10. Jakobsen JK, Jensen JB. DaPeCa-2: Implementation of fast-track clinical pathways for penile cancer shortens waiting time and accelerates the diagnostic process - a comparative before-and-after study in a tertiary referral centre in Denmark. Scand J Urol. 2016;50(1):80-87.

11. Jakobsen JK, Krarup KP, Sommer P, et al. DaPeCa-1: diagnostic accuracy of sentinel lymph node biopsy in 222 patients with penile cancer at four tertiary referral centres - a national study from Denmark. $B J U$ Int. 2016;117(2):235-243.

12. Mortensen GL, Jakobsen JK. Patient perspectives on quality of life after penile cancer. Dan Med J. 2013;60(7):A4655.

13. Danish Quality Improvement Program (RKKP) [homepage on the Internet]. Internet Homepage. Available from: http://rkkp.dk/. Accessed 27 August, 2015.

14. KCKS [webpage on the Internet]. Competence Centre for Health Quality and Informatics (KCKS-Vest). Available from: http://www.kcks-vest. dk/kliniske-kvalitetsdatabaser. Accessed 27 August, 2015.

15. KEA [webpage on the Internet]. Competence Centre for Clinical Epidemiology and Biostatistics, North (KCEB-Nord). Available from: http://www.kea.au.dk/en/ClinicalQuality/CentreClinEpiBiostatNorth. html. Accessed 27 August, 2015.
Clinical Epidemiology

\section{Publish your work in this journal}

Clinical Epidemiology is an international, peer-reviewed, open access, online journal focusing on disease and drug epidemiology, identification of risk factors and screening procedures to develop optimal preventative initiatives and programs. Specific topics include: diagnosis, prognosis, treatment, screening, prevention, risk factor modification,

\section{Dovepress}

systematic reviews, risk \& safety of medical interventions, epidemiology \& biostatistical methods, and evaluation of guidelines, translational medicine, health policies \& economic evaluations. The manuscript management system is completely online and includes a very quick and fair peer-review system, which is all easy to use. 